Supporting Information:

\title{
Quantitative Assessment of Copper(II) in Wilson's Disease Based on Photoacoustic Imaging and Ratiometric Surface-Enhanced Raman Scattering
}

\author{
Hongjuan Feng", Qinrui Fü, Wei Dü, Rong Zhu, Xiaoguang Ge, Chenlu Wang, \\ Qingqing Li, Lichao Su, Huanghao Yang, and Jibin Song*
}

MOE Key Laboratory for Analytical Science of Food Safety and Biology, College of Chemistry, Fuzhou University, Fuzhou 350108, China

Corresponding author: jibinsong@fzu.edu.cn

Materials. Sodium citrate (99\%), thiolated methoxy polyethylene glycol (mPEG$\mathrm{SH}$ ), N, N-dimethylformamide (DMF, $\geq 99.5 \%$ ), 2-naphthylthiol (NAT, 99\%), Polyvinylpyrrolidone (PVP), cetyltrimethylammonium bromide (CTAB, 99\%), Lascorbic acid (AA, 99\%), sodium hydroxide (96\%), silver nitrate ( $\geq 99.8 \%)$, tetrachloroauric acid trihydrate (III) $\left(\mathrm{HAuCl}_{4} \cdot 3 \mathrm{H}_{2} \mathrm{O}\right)$, 4-mercaptobenzonitrile (MBN, 99.92\%), poly (N-isopropylacrylamide) (PNIPAM), copper sulfate 
anhydrous (99\%), phosphate buffered saline (PBS), Nitric acid $\left(\mathrm{HNO}_{3}\right)$, Hydrogen peroxide $\left(\mathrm{H}_{2} \mathrm{O}_{2}, 30 \%\right)$. All chemicals were used without further purification. All aqueous solutions were prepared with ultrapure water (18 $\mathrm{M} \Omega)$. Wilson's disease (WD) mice with mutation in the APT7B gene were obtained from The Jackson Laboratory (USA). Clinical urine samples were Collect from Ai Di Kang Medical Laboratory. The solutions of $\mathrm{K}^{+}, \mathrm{Na}^{+}, \mathrm{Ag}^{+}, \mathrm{Mg}^{2+}, \mathrm{Ca}^{2+}, \mathrm{Fe}^{3+}$ and $\mathrm{Mn}^{2+}$ ions were prepared with chloride. $\mathrm{Co}^{2+}$ and $\mathrm{Pb}^{2+}$ solutions were made from their nitrates. $\mathrm{Zn}^{2+}$ and $\mathrm{Cu}^{2+}$ solutions were made from their sulfates.

Characterization. TEM images were captured using the Hitachi HT7700 transmission electron microscope at an acceleration voltage of $100 \mathrm{KV}$. The zeta potential of the nanoparticles was determined by a Malvern Zetasizer Nano ZS instrument. UH-4150 ultraviolet-visible spectrophotometer (Hitachi, Japan) was used to measure the absorption spectra. The red shift phenomenon before and after aggregation of AuNNP-NAT@MBN/PNIPAM was determined by the change of absorption intensity at different wavelengths. Renishaw Invia Raman Microscopy (Renishaw, UK) was used to obtain Raman (SERS) spectrum in the range of $1200-2500 \mathrm{~nm}$. PA imaging was performed using VisualSonic Vevo 3100 LAZR system $(40 \mathrm{MHz}, 256$-element linear array transducer) on a small animal model (WD). ICAP-RQ was used to detect the concentration liver $\mathrm{Cu}^{2+}$ in mice. 


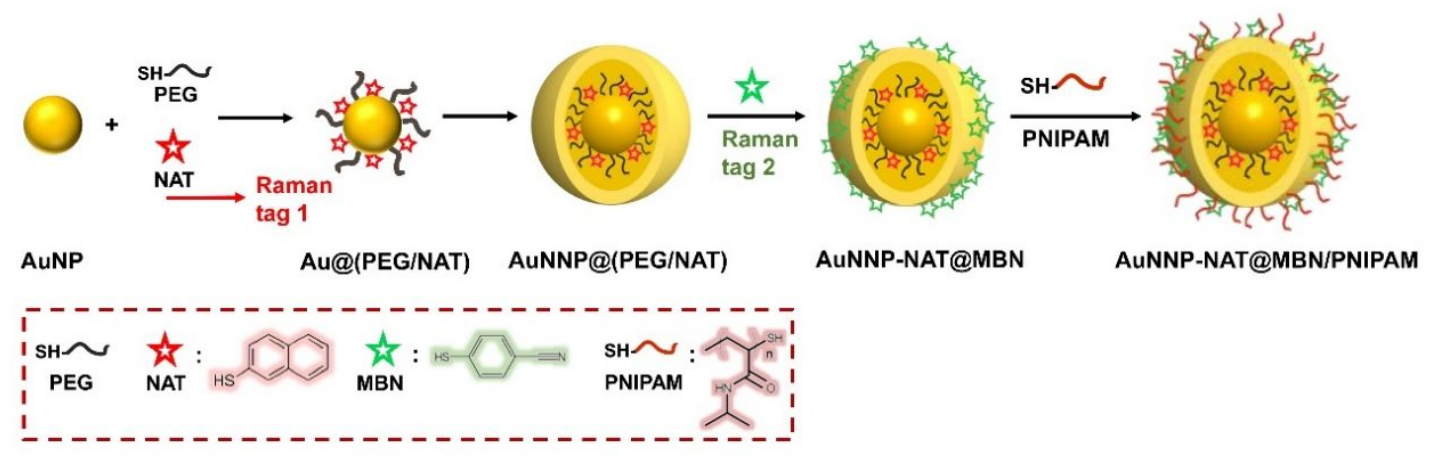

Figure S1. Schematic diagram showing the synthesis steps of AuNNPNAT@MBN/PNIPAM.
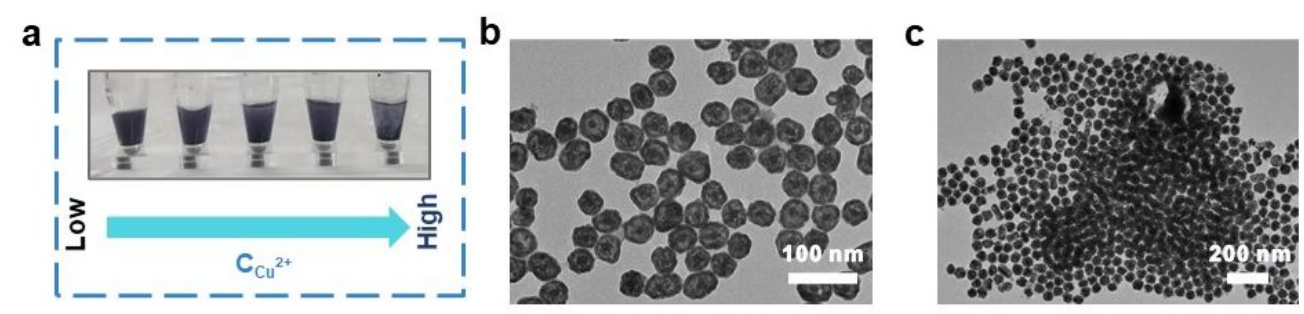

d

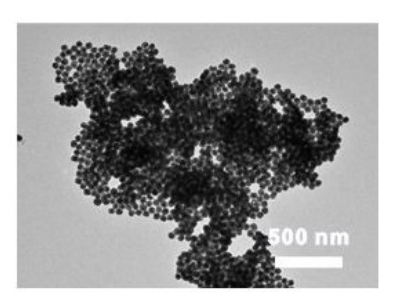

e

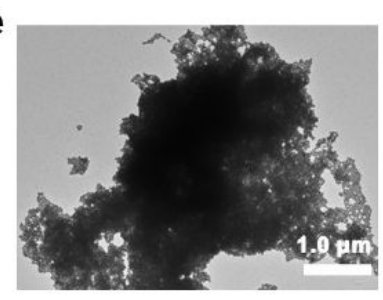

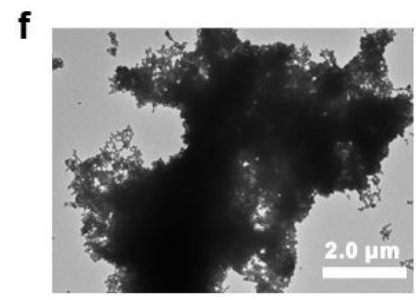

Figure S2. The photographic image (a) and TEM images (b-f) of the AuNNPNAT@MBN/PNIPAM solutions after incubating with $\mathrm{Cu}^{2+}$ of different concentrations $(0,10,50,100,500 \mu \mathrm{M})$ at $37^{\circ} \mathrm{C}$ for $4 \mathrm{~h}$, respectively. 

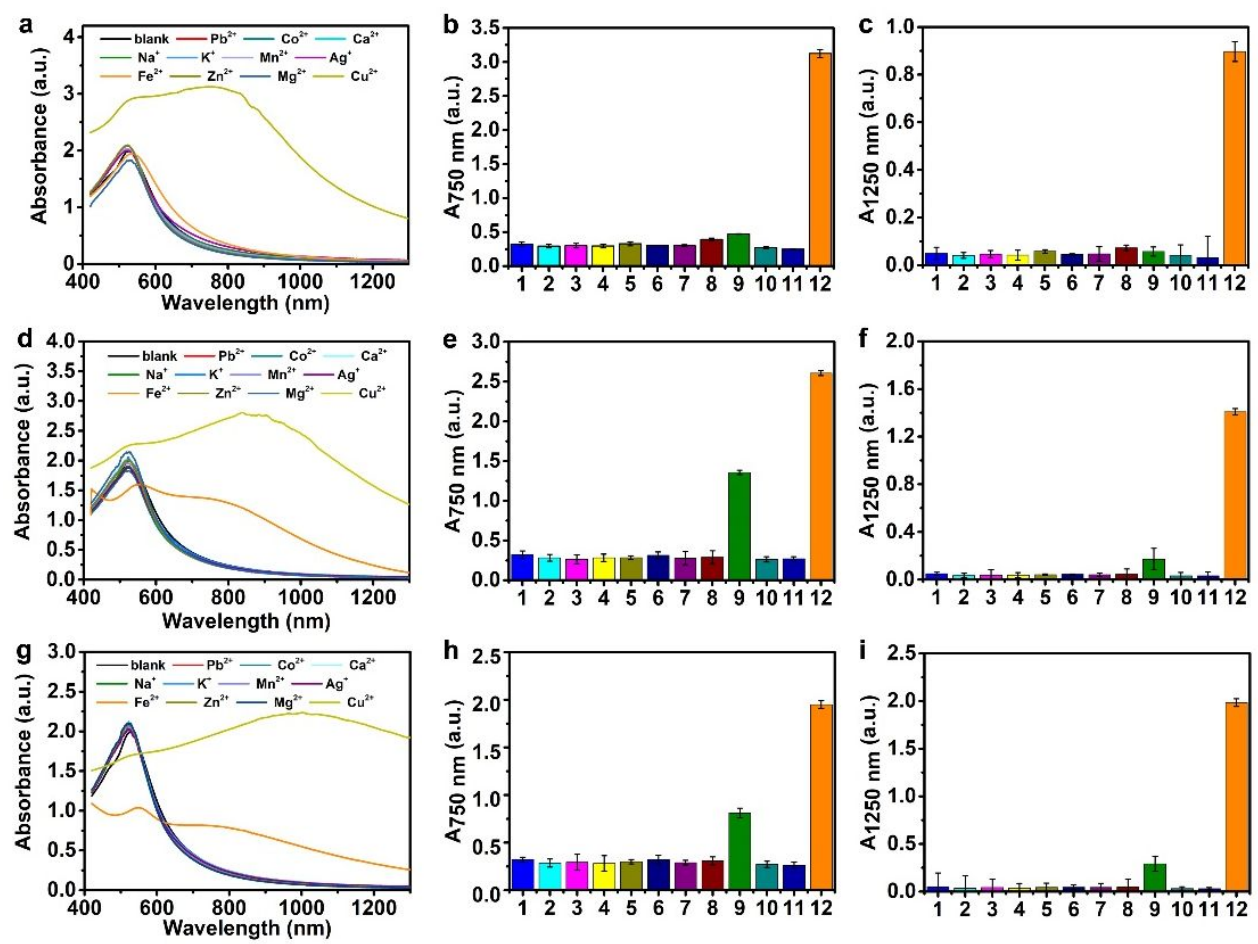

Figure S3. (a, d, and g) The visible-near infrared (vis-NIR) absorption spectra of 0.866 nM AuNNP-NAT@MBN/PNIPAM in the absence (blank) and presence of $\mathrm{Cu}^{2+}(1 \mathrm{mM}, 3 \mathrm{mM}$, and $5 \mathrm{mM})$, or in the presence of other metal ions $(1 \mathrm{mM}$, $3 \mathrm{mM}$, and $5 \mathrm{mM}$, i.e., $\mathrm{Pb}^{2+}, \mathrm{Co}^{2+}, \mathrm{Ca}^{2+}, \mathrm{Na}^{+}, \mathrm{K}^{+}, \mathrm{Mn}^{2+}, \mathrm{Ag}^{+}, \mathrm{Fe}^{3+}, \mathrm{Zn}^{2+}$, and $\left.\mathrm{Mg}^{2+}\right)$ at $37{ }^{\circ} \mathrm{C}$ for $4 \mathrm{~h}$, respectively. Different ions reacted with AuNNPNAT@MBN/PNIPAM individually. The absorbance at $750 \mathrm{~nm}(\mathrm{~b}, \mathrm{e}$, and $\mathrm{h})$ and the absorbance at $1250 \mathrm{~nm}(\mathrm{c}, \mathrm{f}$, and $\mathrm{i})$ of the above reaction mixtures in a, d, and g, respectively. Error bars represent standard deviation $(n=3) .1$ : blank; 2 : $\mathrm{Pb}^{2+} ; 3: \mathrm{Co}^{2+} ; 4: \mathrm{Ca}^{2+} ; 5: \mathrm{Na}^{+} ; 6: \mathrm{K}^{++} ; 7: \mathrm{Mn}^{2+} ; 8: \mathrm{Ag}^{+} ; 9: \mathrm{Fe}^{3+} ; 10: \mathrm{Zn}^{2+} ; 11: \mathrm{Mg}^{2+}$, 12: $\mathrm{Cu}^{2+}$ 

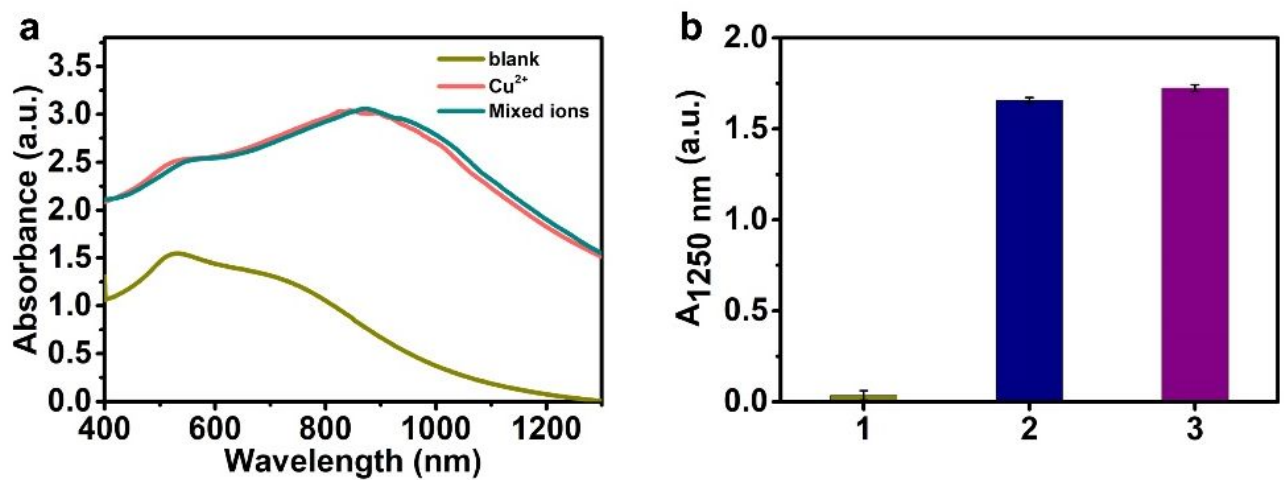

Figure S4. (a) The vis-NIR absorption spectra of $0.866 \mathrm{nM}$ AuNNPNAT@MBN/PNIPAM in the absence (blank) and presence of $\mathrm{Cu}^{2+}$, or in the presence of the mixed ions consist of $\mathrm{Fe}^{3+}, \mathrm{Mg}^{2+}, \mathrm{Cu}^{2+}, \mathrm{Mn}^{2+}$ and $\mathrm{Co}^{2+}$ at $37^{\circ} \mathrm{C}$ for $4 \mathrm{~h}$, respectively. The concentration of each ions is $3 \mathrm{mM}$. (b) The absorbance at $1250 \mathrm{~nm}$ of the above reaction mixtures in a. 1: blank; 2 : $\mathrm{Cu}^{2+}$; 3: mixed ions. Error bars represent standard deviation $(n=3)$.

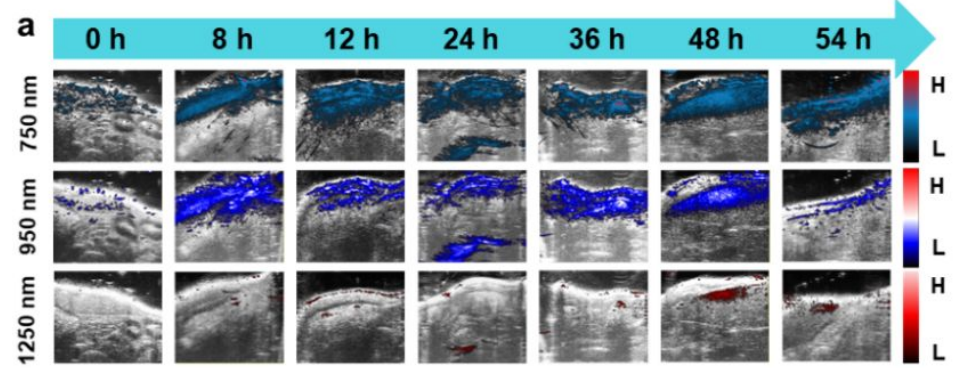

b

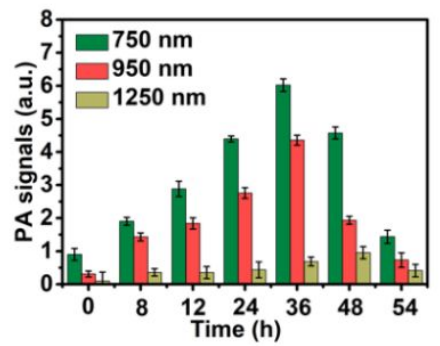

Figure S5. (a) Time-course PA images of liver at $750 \mathrm{~nm}, 950 \mathrm{~nm}$ and $1250 \mathrm{~nm}$ after mouse with $\mathrm{Cu}^{2+}$ abnormality was intravenously injected with $100 \mu \mathrm{L}$ of 0.866 nM AuNNP-NAT@MBN/PNIPAM dispersed in PBS. (b) Corresponding quantified average PA intensity at $750 \mathrm{~nm}, 950 \mathrm{~nm}$ and $1250 \mathrm{~nm}$ in a. Error 
bars represent standard deviation $(n=3)$.

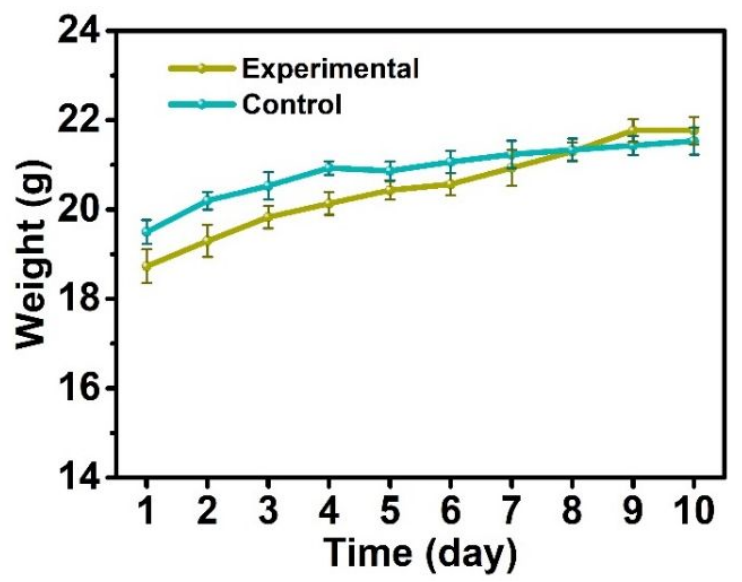

Figure S6. The body weight changes of mice with hereditary Wilson's disease after various treatments. Experimental: mice were intravenously injected with $100 \mu \mathrm{L}$ AuNNP-NAT@MBN/PNIPAM (0.866 nM, dispersed in PBS). Control: mice were intravenously injected with $100 \mu \mathrm{L}$ PBS. Error bars represent standard deviation $(n=3)$.

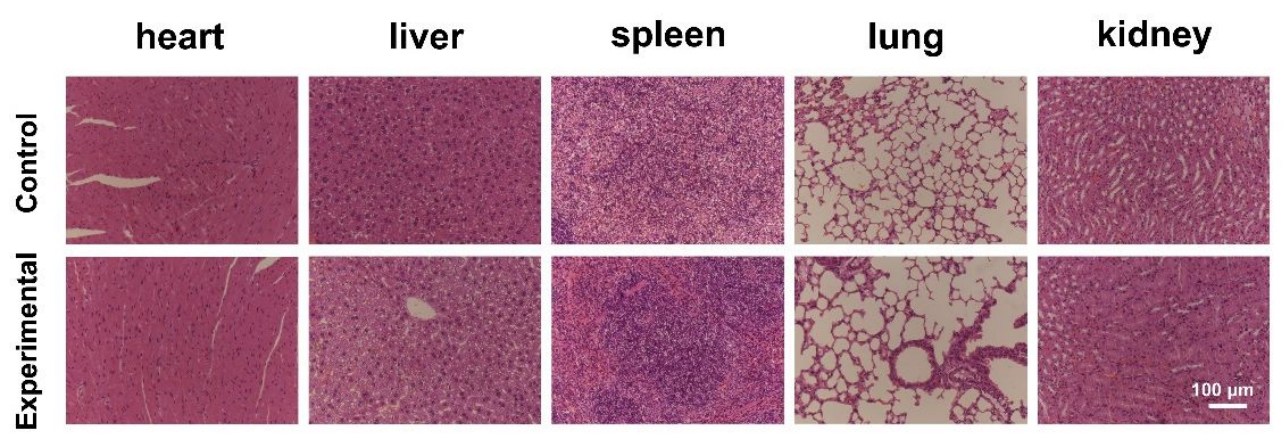

Figure S7. H\&E staining images of tissue sections of the main organs (heart, liver, spleen, kidney and lung) from mice with hereditary Wilson's disease at 24 $h$ post various treatments. Experimental: mouse was intravenously injected with $100 \mu \mathrm{L}$ AuNNP-NAT@MBN/PNIPAM (0.866 nM, dispersed in PBS). Control: mouse was intravenously injected with $100 \mu \mathrm{L}$ PBS. Error bars represent 
standard deviation $(n=3)$. scale bar: $100 \mu \mathrm{m}$.

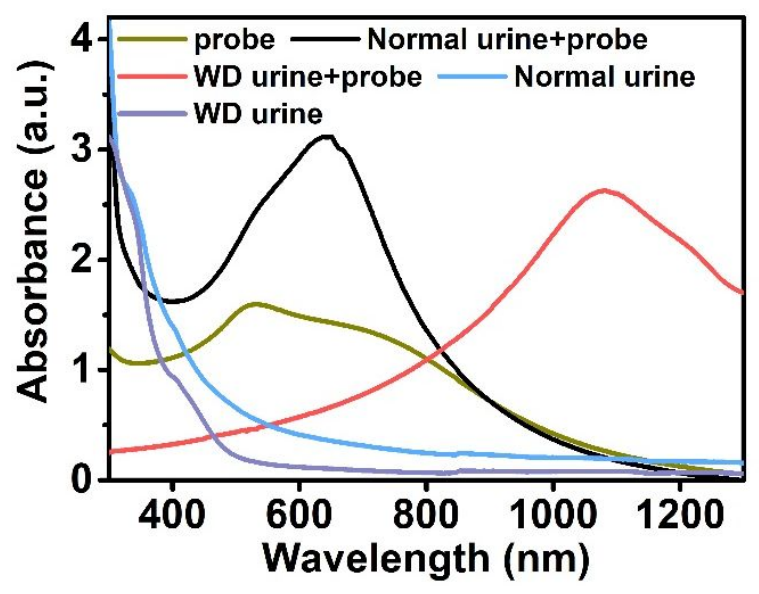

Figure S8. Ultraviolet-visible-near infrared (UV-vis-NIR) absorption spectra of AuNNP-NAT@MBN/PNIPAM (probe), urine sample from normal person (Normal urine) and urine sample from Wilson's patient (WD urine), Normal incubated with 0.866 nM AuNNP-NAT@MBN/PNIPAM at $37^{\circ} \mathrm{C}$ for $4 \mathrm{~h}$ (Normal urine+probe), and WD incubated with 0.866 nM AuNNP-NAT@MBN/PNIPAM at $37^{\circ} \mathrm{C}$ for $4 \mathrm{~h}$ (WD urine+probe).

Table S1. The equation used to calculate the concentration of AuNNP solution. The size of each gold atom (Au atom) is $0.017 \mathrm{~nm}^{3}$. According to equation S1a and $\mathrm{S} 1 \mathrm{~b}$, the number of Au atoms contained in $17 \mathrm{~nm}$ AuNP $\left(\mathrm{N}_{\mathrm{Au}}\right.$ atoms per $17 \mathrm{~nm}$ $\mathrm{Au}$ ) can be calculated, and the calculated value is $1.51 * 10^{5}$, where $r_{1}$ represents the radius of $17 \mathrm{~nm}$ AuNP. The molar mass of $17 \mathrm{~nm}$ AuNP $\left(\mathrm{M}_{17 \mathrm{~nm} \mathrm{Au}}\right)$ is $197 \mathrm{~N}$ atom, and the calculated result is $2.975^{*} 10^{5} \mathrm{~g} / \mathrm{mol}$. According to equation S1c and S1d, the volume of $52 \mathrm{~nm}$ AuNNP ( $\left.\mathrm{V}_{\text {AuNNP }}\right)$ and the volume of Au shell (V 
Au shell) can be calculated, respectively, where $r_{2}$ and $r_{3}$ represents the radius of $52 \mathrm{~nm}$ AuNNP and the gap distance of the core-shell structure, respectively. Using equation S1e, the number of $17 \mathrm{~nm}$ Au contained in $52 \mathrm{~nm}$ AuNNP $\left(\mathrm{N}_{17}\right.$ nm AunPs per AuNNP) is calculated to be 27 . The molar mass of $52 \mathrm{~nm}$ AuNNP $\left(\mathrm{M}_{52}\right.$ $\mathrm{nm}$ AuNNP) is $27^{*} 197^{*} \mathrm{~N}$ atom, and the calculated result is $8.03^{*} 10^{8} \mathrm{~g} / \mathrm{mol}$. Finally, the calculation equation S1f of the $52 \mathrm{~nm}$ AuNNP substance concentration (C $52 \mathrm{~nm}$ AuNNP) is $52 \mathrm{~nm}$ AuNNP mass ( $\mathrm{m}_{52} \mathrm{~nm}$ AuNNP) / $52 \mathrm{~nm}$ AuNNP molar mass

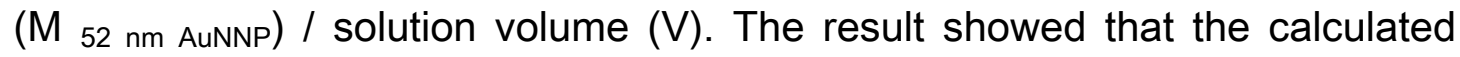
concentration of $52 \mathrm{~nm}$ AuNNP is $1.444 \mathrm{nM}$.

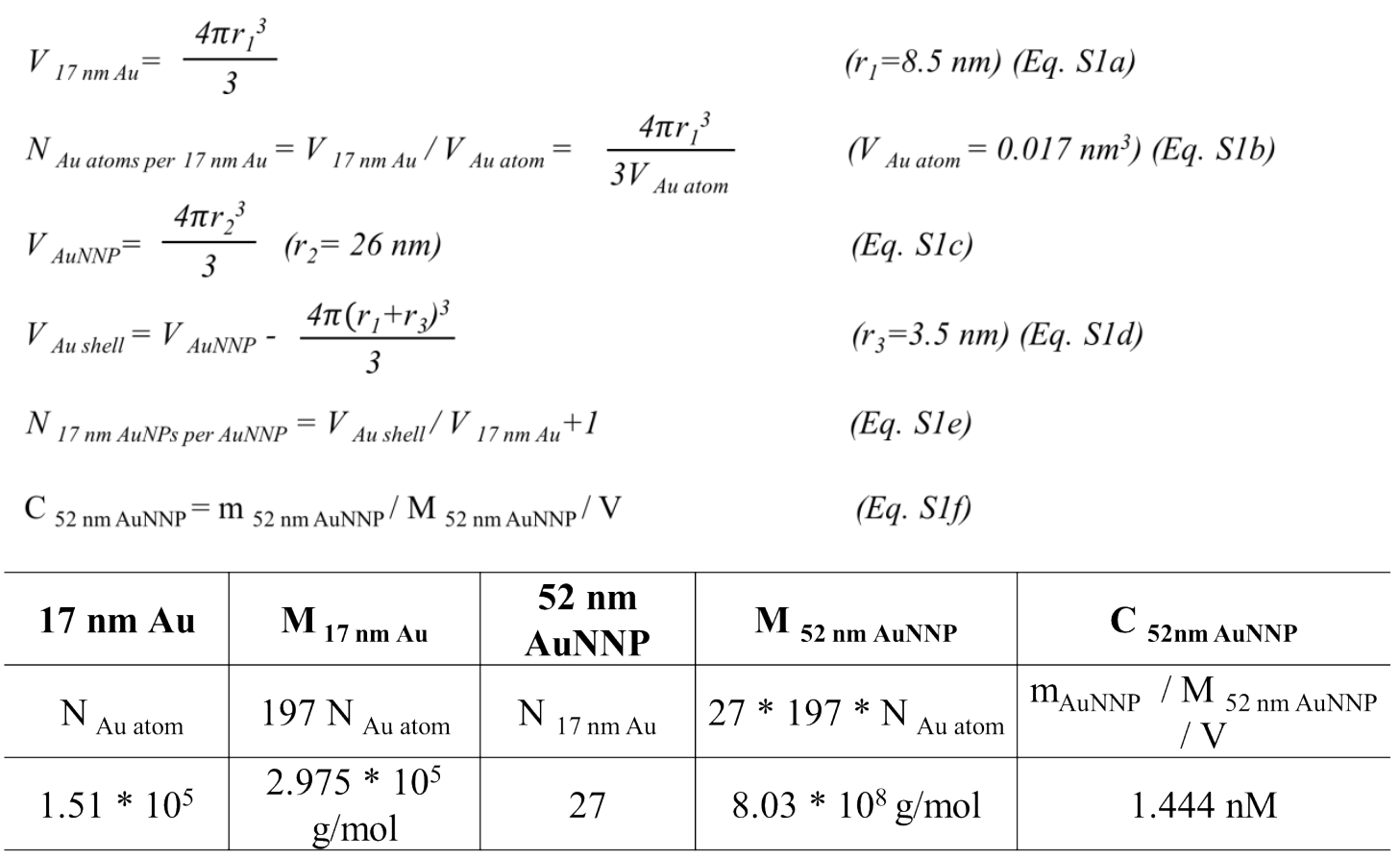


Table S2. The copper ion concentration in the livers of mice with Wilson's disease and normal mice measured by ICP-MS.

\begin{tabular}{c|c|c|c|c|c|c}
\hline $\begin{array}{c}\text { Linear regression } \\
\text { equation }\end{array}$ & $\mathbf{R}^{2}$ & $\begin{array}{c}\text { Linear } \\
\text { range }\end{array}$ & $\begin{array}{c}\mathbf{W}_{\text {Normal }} \\
(\mathbf{m g} / \mathbf{K g})\end{array}$ & $\begin{array}{c}\mathbf{W}_{\mathbf{W D}} \\
(\mathbf{m g} / \mathbf{K g})\end{array}$ & $\begin{array}{c}\mathbf{C}_{\text {Normal }} \\
(\mathbf{m M})\end{array}$ & $\begin{array}{c}\mathbf{C}_{\mathbf{W D}} \\
(\mathbf{m M})\end{array}$ \\
\hline $\mathrm{y}=7462.35 \mathrm{x}-$ & 0.995 & $10 \sim 200$ & $25.914 \pm$ & $225.263 \pm$ & $0.318 \pm$ & $3.054 \pm$ \\
84889.8 & & $\mathrm{ppb}$ & 0.221 & 1.007 & 0.003 & 0.027 \\
\hline
\end{tabular}

